$M=2=-1=$

\title{
China launches primate centre to broaden medical use of monkeys
}

David Cyranoski, Tokyo

Biologists in China plan to capitalize on the region's easy access to primates to set up a global resource for disease research.

The centre, based at Sun Yat-sen University in Guangzhou, southern China, will use locally obtained primates to build up a library of stem cells. It will also develop large colonies of transgenic primates for use as models of human disease.

Together, Sun Yat-sen University and local government have invested about US $\$ 1$ million in the project, which is tentatively named the Center for Stem Cell Biology and Tissue Engineering.

The centre is being established in close cooperation with Bruce Lahn, a geneticist at the University of Chicago, Illinois. It aims to explore areas in which the use of primates has so far been limited, such as neurological disease and developmental biology. In the United States and Europe, primate research in these areas is restricted because of the high cost and lengthy life cycle of the animals, as well as criticism from animal-rights activists.

Cost should not be a problem for the new centre, says its director Peng Xiang, a former postdoctoral student of Lahn's. US researchers often pay US\$5,000 per animal, but the centre will pay about one-tenth of that, Xiang says, obtaining several hundred rhesus macaques and crab-eating monkeys from a primate breeding centre nearby.

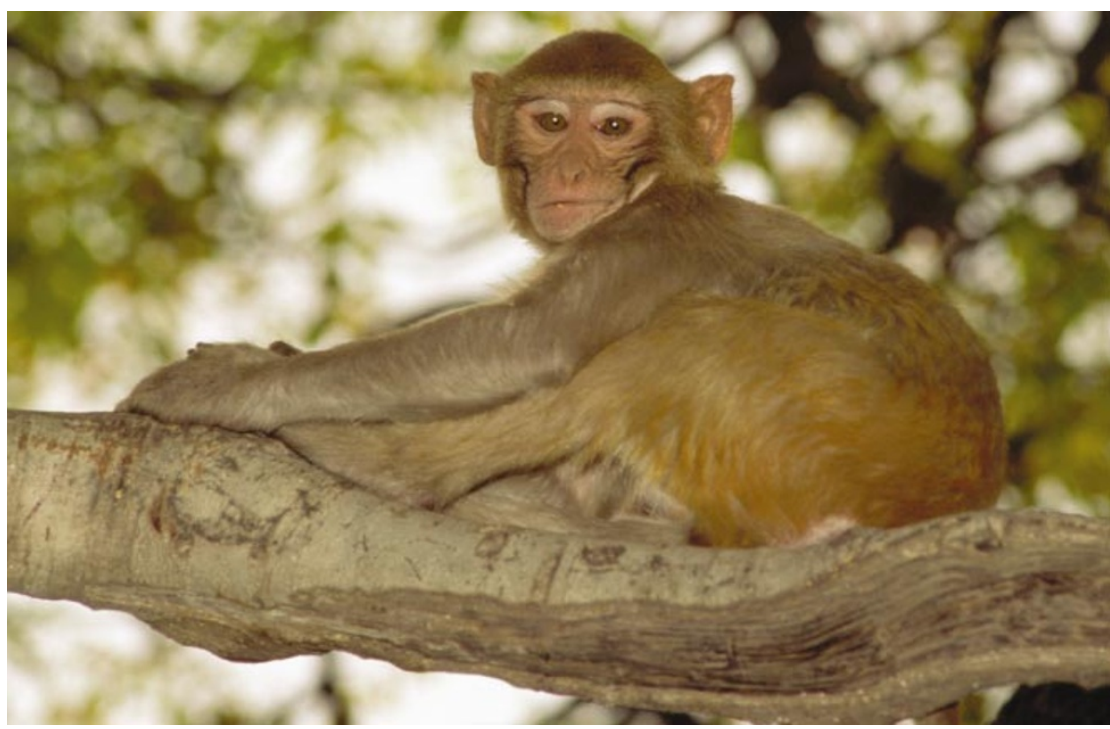

Rhesus monkeys are among the primates that Chinese researchers will use to model human disease.

Xiang is also looking at obtaining inbred animals from an island south of China, although this may prove to be controversial as the removal of monkeys from the wild has upset conservationists (see Nature 417, 684-687;2002).

Lahn believes that the centre could redefine primate research. "China's unique advantages in the field could propel it into a position of international leadership," he says.
If so, it would bring many experiments, currently done in mice, one step closer to humans. "Primate research has tremendous promise for bridging the gap between what's known about the biology of mice and what we want to know about human disease," says Gerald Schatten of the University of Pittsburgh, Pennsylvania, who has pioneered transgenic and cloning studies in primates.

Xiang argues that many experiments

\section{Are China's bioethics under control?}

\section{China has similar protocols on biological} experimentation to other countries, researchers there often argue, but it is less bureaucratic in implementing them.

As recent health problems with AIDS and SARS have demonstrated, however, the Chinese government may lack the means to enforce strict regulations throughout the vast country, even if it wanted to.

As a result, research ethics are being policed at the local level - or they rely on the goodwill of China's researchers, and their appetite for international acceptance.

"Our first priority is to publish papers in the major journals, and we don't want to get rejected on the basis of a violation of ethical standards," says Linsong Li, director of Peking University's Stem Cell Research Center.

The Chinese government has been preparing ethical guidelines for biologists for more than a year, but their publication has repeatedly been delayed. The document is expected to cover human stem cells and to include some restrictions on other procedures, such as xenotransplantation.

In the meantime, some local organizations have taken matters into their own hands. The National Human Genome Center in Shanghai, for example, in spring 2002 drafted its own guidelines for research on human embryonic stem cells.

Even if major centres have regulations in place, it is hard to know what is happening in the rest of China. Although human rights are taken seriously, the idea of humane treatment of animals has yet to be cemented, says Huanming Yang, director of the Beijing Genomics Institute. "We're still at the beginning with animal rights," he adds.

Chinese biologists are highly sensitive to the outside perception that their country has lax bioethical standards, says Bruce Lahn of the University of Chicago. Many Chinese research leaders were trained abroad and follow international rules, he argues. 
using mouse models have been inconclusive because of the great dissimilarity between humans and mice.

Already, 15 researchers are working at the new centre. According to Lahn, researchers will start with 100-200 monkeys this autumn and build to three times that number over the next few years. The founders of the centre say that they will adhere to Western-level research ethics, although doubts have sometimes been expressed about China's ability to police such ethics (see 'Are China's bioethics under control?', previous page).

The centre is expected to build on some of Schatten's pioneering work in primates, including efforts to clone a rhesus monkey (C. Simerly et al. Science 300, 297; 2003), and a gene-transfer experiment that achieved low-level expression of a jellyfish gene for a green fluorescent protein in another rhesus monkey (A. W. S. Chan, K. Y. Chong, C. Martinovich, C. Simerly and G. Schatten Science 291, 309-312;2001).

According to Xiang, the centre will try to improve on previous transgenic experiments by using several different viruses to introduce the genes. The viruses will either be allowed to invade a newly fertilized egg on their own or will be injected directly into an egg, as the researchers look for the best way to create primates with active transgenes. The resulting animals could be used as models for neurodegenerative diseases such as Huntington's, Xiang says. The centre will also study the function of developmental genes such as hedgehog, focusing in particular on their role in brain development.

Another of the centre's aims is to establish itself as a global source of primate stem cells of various types and stages of development. The supply of primate stem cells will "be valuable in a few years, when clinical trials of stem-cell therapies are closer to reality and real preclinical work is necessary", says Daniel Salomon of the Scripps Research Institute in La Jolla, California.

But Salomon doubts whether the centre's plan to create a pool of inbred monkeys will provide a useful model for disease research. "Inbred mice have been extraordinarily useful for basic studies," he says, "but the translation to human patients that are everything but inbred has been problematic."

The new centre's managers are already wary of ethical charges that may be levelled against their work. They have backed away, for example, from an earlier plan to grow tissue from human cells in primates for implantation back into humans. Such 'xenotransplantation' is seen by many experts as dangerous because of the risks of interspecies infection.

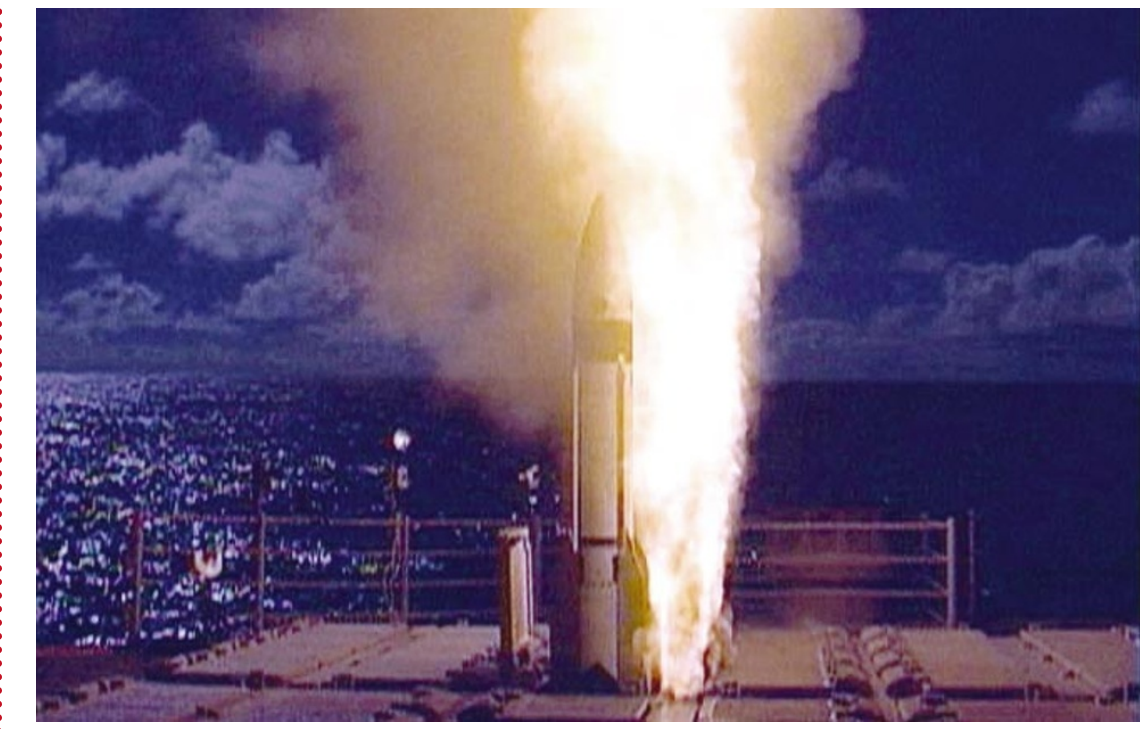

Blast off: plans to use short-range interceptor missiles for US defence face technical challenges.

\section{Experts find fault with US plan to intercept missiles at source}

\section{Geoff Brumfiel, Washington}

Defending the United States against longrange missile attack may be even more technically challenging than was previously thought, a group of physicists has warned.

In a study due to be published this week, a team from the American Physical Society examined the possibility that enemy missiles could be destroyed within four minutes of launching. The idea has support in US military and scientific circles, as missiles are most visible as targets during this period.

The physicists conclude that interceptor missiles will need to be placed close to enemy territory to reach a missile in this early phase. Even then, the study says, decision-makers will have only seconds to decide whether to launch an interceptor. And if the missile destroys its target, the warhead might survive and fall into a civilian area. "The problems are extremely difficult," says Daniel Kleppner, a physicist at the Massachusetts Institute of Technology (MIT), and co-chair of the study.

The United States spends about $\$ 8$ billion a year on developing systems for shooting down incoming missiles. Most of this goes to interceptors being installed at Fort Greely, Alaska, which are designed to collide with a warhead at the apex of its flight. But many previous studies have cast doubt on this strategy, as the warheads are small and difficult to hit, and the interceptors can be fooled by balloons and other decoys. Many experts have argued that it would be better to stop missiles at the start of their flight, when the warhead is attached to fuel tanks, creating a larger target.

The physicists show, however, that interceptor missiles would have to be placed within $400-1,000 \mathrm{~km}$ of the launch site to hit their target. For small, coastal countries such as North Korea, interceptors could be fired from US ships. But action against countries such as Iran would require neighbouring states to host US missile bases. Interceptors would also need to reach speeds of up to $10 \mathrm{~km}$ per second - much faster than current systems.

A more vexing problem is the risk that warheads from intercepted missiles could hit civilian targets. "A nuclear warhead is designed to be very robust," says Ted Postol, an MIT physicist and missile-defence expert. Although the chances of hitting a populated area are small, Postol argues that the warhead is likely to land in a country not involved in any conflict.

The study also looks at two unconventional proposals for early interception of ballistic missiles: an airborne laser that would fire at enemy missiles as they take off, and space-based interceptors that would descend on a missile. The laser could be effective if it were sited within $600 \mathrm{~km}$ of the launch site, say the authors, but the space system would be impossible to implement without about 1,000 interceptors in orbit. That would require at least a "five- to tenfold" increase in the capacity of US space-launch systems.

The report may not change many minds on this partisan topic, but it will inform the debate over whether to catch missiles as they take off, says Philip Coyle, senior adviser to the Center for Defense Information in Washington DC. "This study is the first honest-toGod assessment of what's scientifically possible," he says.

www.aps.org 